THE LIVED EXPERIENCES OF FIRST RESPONDERS DURING EMERGENCY EVENTS INVOLVING CHILDREN

\begin{tabular}{c} 
A Dissertation \\
presented to \\
The Faculty of the Graduate School \\
University of Missouri \\
In Partial Fulfillment \\
of the Requirements for the Degree \\
Doctor of Philosophy \\
LINDSEY M. MURPHY \\
\hline
\end{tabular}

May 2019 


\section{APPROVAL}

The undersigned, appointed by the dean of Graduate School, have examined the dissertation entitled

\section{THE LIVED EXPERIENCES OF FIRST RESPONDERS} DURING EMERGENCY EVENTS INVOLVING CHILDREN

Presented by Lindsey M. Murphy,

A candidate for the degree of Doctor of Philosophy, And hereby certify that, in their opinion, it is worthy of acceptance.

Dr. Sarah Killoren

Dr. Russell Ravert

Dr. Tashel Bordere

Dr. Brian Houston 


\section{DEDICATION}

A special thanks to my entire family for their enduring support throughout this doctoral journey. To my husband, for diligently supporting me through long nights of writing and all the emotional highs and lows; you have been my rock. Without your support, understanding, and relentless encouragement this would have never been possible. To my son, for always knowing exactly when and how to brighten my day and reminding me to seize opportunities for play. You are such an inspiration and joy to be around. And to my future baby girl, for being the best motivation to finish this part of the journey. 


\section{ACKNOWLEDGEMENTS}

I am especially grateful for Dr. Sarah Killoren, Associate Professor in Human Development and Family Science, for taking me under her wing, listening to my career goals, and being the best advocate to help me pursue those goals in research, service, and teaching. To Dr. Chris Proulx, Associate Professor and Interim Department Chair in Human Development and Family Science, thank you for being the change factor in my academic career - helping to validate my desire for a $\mathrm{PhD}$ to reach my alternative career goals. Together, you two have modeled perfectly what it means to be effective leaders and women in academia, while also maintaining your most important roles of mom and wife. Thank you for being this example for me, you each have demonstrated exactly the advisor, scientist, leader, and person I strive to be each day.

I am appreciative to all those whom I have had the pleasure to work with during this and other related projects. Each of the members of my Dissertation Committee (Dr. Sarah Killoren, Dr. Russell Ravert, Dr. Tashel Bordere, Dr. Brian Houston) have provided me with extensive personal and professional guidance that I will be forever indebted. To the Midwest Metropolitan Fire Department for trusting me, inviting me in, and allowing me to learn from each of your incredible first responders, thank you for this and all the service you provide to our communities.

Finally, I am thankful for the generous financial support of the Research Activity Fund from the Department of Human Development and Family Science and the Eleanor Berger Blumenthal Fellowship, without this support this research would not have been possible. 


\section{TABLE OF CONTENTS}

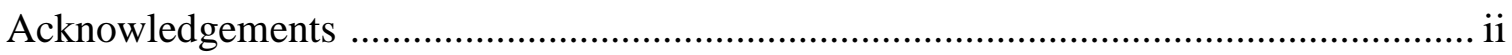

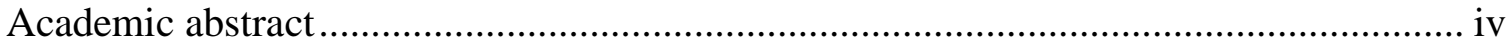

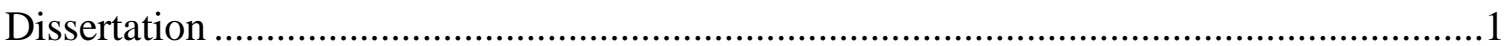

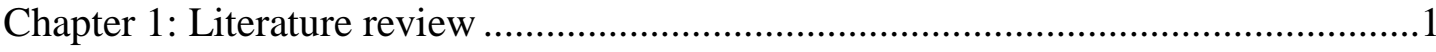

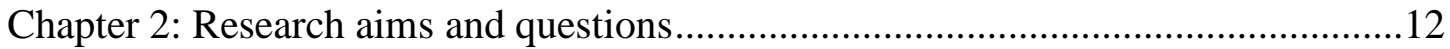

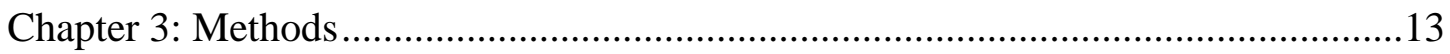

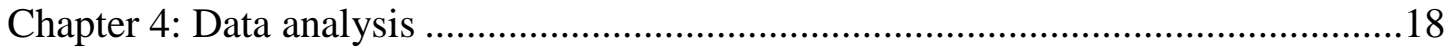

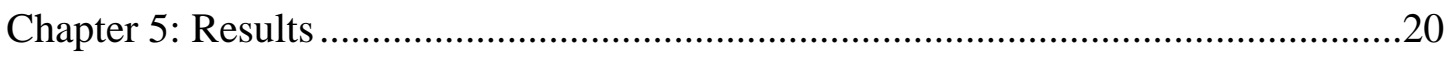

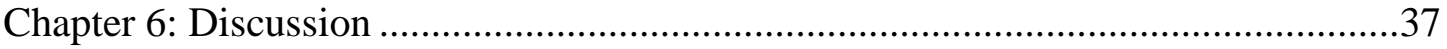

Chapter 7: Future Research Directions ...................................................................44

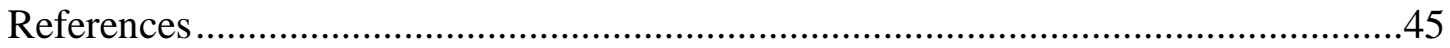

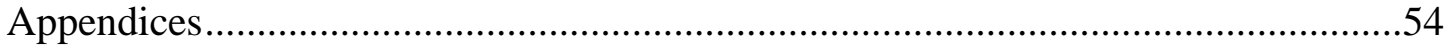

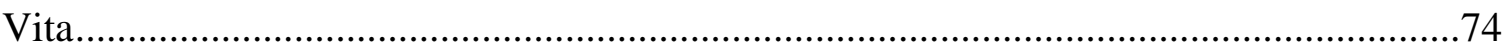




\title{
THE LIVED EXPERIENCES OF FIRST RESPONDERS \\ DURING EMERGENCY EVENTS INVOLVING CHILDREN
}

\author{
Lindsey Murphy
}

Dr. Sarah Killoren, Dissertation Supervisor

\section{ACADEMIC ABSTRACT}

Given the fact that first responders are often the first point of contact with children in emergency events that could potentially be appraised as traumatic and have long lasting detrimental effects, the purpose of this study was to examine the lived experience of first responders within a Midwest Metropolitan Fire Department during emergency events involving children. Using descriptive phenomenology methods, 16 interviews were conducted with eight first responders. Results indicated four phenomena related to experienced child reactions during emergency events 1) lack of reactions, 2) emotion-based reactions, 3) information seeking reactions, and 4) observant reactions. First responders identified their role in supporting children on the scene in using distraction, providing calming and reassurance, and providing education. Current systems of emotional support identified by first responders included family members, neighbors, police officers, and hospital staff. Gaps in services identified by first responders included specialized and dedicated support for children and effective first responder training. 


\section{Chapter 1: Literature Review}

\section{Purpose of the Study}

The purpose of this study was to gain insight into the lived experiences of first responders during emergency events involving children (0-18 years old). Understanding first responders' experiences provides insight into the events themselves, first responders' perceptions of their role(s) in supporting the children and the needs of children, and the systems of care and support currently in place for children involved in these events. The long-term goal of this research is to reduce the traumatic effects of emergency events on children by providing evidence-based, systematic trauma-informed care in the acute aftermath of these events. Understanding first responders lived experiences in these situations is vital to developing informed models of support to decrease potential traumatic effects on children.

\section{Why First Responders?}

It is essential to recognize that first responders are not alone in their efforts to provide support to community members experiencing emergency events. Numerous other agencies and organizations collaborate to provide well-rounded trauma informed systems of care and support (e.g., educational systems, first responders, healthcare systems, juvenile justice systems). Each have their own set of responsibilities, perspectives, and approaches to caring for children after traumatic situations, with varying degrees of trauma-informed approaches being implemented (Ko et al., 2008). First responders are in a unique position to mitigate traumatic effects of events, as they often are the first people to come into contact with the individuals involved. First responders' primary role on the scene is to assess and maintain safety, provide emergency medical support (e.g., maintain 
the airway, breathing, and circulation of victims), and to protect evidence. It is unknown what, if any, role first responders perceive themselves to have in the psychological support and emotional care of those they serve. It is also unknown if such services are a reasonable expectation based on competing demands on the first responder. Once it is known how first responders perceive their role and their preparedness in trauma-informed care, a systematic approach to increasing the application of these services to children impacted by these events can be best developed. This is the only study to utilize first responders as informants to investigate first responders' perceptions of their role and the children's needs, as well as, the current systems of care during emergency events.

Despite their titles as first responders, there are specific differences in the training, roles, and responsibilities amongst types of first responders. For instance, law enforcement officers are primarily called into situations to protect people or property from harm, enforce laws, and to secure evidence. Firefighters are primarily called into situations to provide medical support or physical rescue from a variety of hazards (e.g., vehicle incidents, chemical spills, fires). It is also important to recognize that due to the nature of their work, firefighters are often cross-trained as paramedics and/or emergency medical technicians (EMT). Due to the major differences in roles and responsibilities and, therefore, types of calls they respond to, this study focused on first responders within the fire department (e.g., paramedics, EMTs, firefighters) due to this group often being first on the scene during medical and hazardous events.

\section{Defining Traumatic Event}

A traumatic event is one that threatens injury, death, or physical integrity of self or others, while also causing horror, terror, or helplessness at the time it occurs (APA, 
2008; Hawkins, 2009). A traumatic event is not defined by the type of event, but, rather, the combination of a threat to safety, fear, and helplessness. It is one's perception of danger and their personal psychological reaction that comprises their own appraisal of an event being traumatic or not (Stallard, Velleman, \& Baldwin, 2001). For the purposes of the study, the term traumatic event will be used to describe events that have the potential to be personally appraised as traumatic.

Factors increasing risk of an event being appraised as traumatic. Importantly, there are several factors that have been shown to influence how children respond to traumatic situations that can prove useful when assessing a child's risk and vulnerability to negative psychological and neurobiological outcomes from traumatic events. These factors include exposure and personal, family, and social factors. Evident in research is that there is a dose-response relationship between trauma exposure and negative effects on individuals (Furr, Comer, Edmunds, \& Kendall, 2010; Pfefferbaum, Jacobs, Griffin, \& Houston, 2015a). The more one experiences during a traumatic event, the more likely they are to experience negative effects. It is important to note that proximity to an event does not equate to exposure, but rather there are specific aspects of exposure that determine risk. Furr and colleagues (2010) identified these aspects as: perception of threat; subjective reactions of others; extent of disruption, destruction, injury and death; child-specific disaster experiences such as being injured, witnessing the disaster or its physical effects, and losing a loved one. Personal factors include: developmental age (Masten \& Narayan, 2012; Wooding \& Raphael, 2004), pre-event history (Halpern \& Vermeulen, 2017; Pfefferbaum, Jacobs, Griffin, et al., 2015a), and coping (Halpern \& Vermeulen, 2017; Pfefferbaum, Jacobs, Griffin, \& Houston, 2015b). 
In addition, it is essential to recognize that families are the central circle that provide a safe context for children. Children's reactions are heavily influenced not only by a family's demographics (Hawkins, 2009), but also their caregiver's reactions to the traumatic event, the quality of their relationship to that caregiver, the interactions between the two that take place, and their parenting style (Norris et al., 2002; Pfefferbaum, Jacobs, Houston, \& Griffin, 2015). Finally, social support has been associated with better adjustment and psychological outcomes after traumatic events. Social support comes in many forms (e.g., parents, mentors, teachers, friends, communities) and has been associated with better adjustment and psychological outcomes post-traumatic event (Pfefferbaum, Jacobs, Houston, et al., 2015). Unfortunately, there is an inverse relationship between available social support and traumatic event exposure (Banks \& Weems, 2014). Therefore, support services must be aimed at increasing social opportunities for support. When survivors become overwhelmed it is easy to lose hope when few social supports are available, it is imperative that those affected receive social support as quickly as possible (Halpern $\&$ Vermeulen, 2017).

In addition to the myriad factors listed above, the cause (i.e., natural or manmade), size (e.g., scope and intensity), expectedness (e.g., warning or sudden), and timing (e.g., holidays, day/night, winter/summer) of the event greatly impacts the way individuals and communities respond and cope with traumatic events (Halpern \& Vermeulen, 2017). Regardless, nearly everyone that experiences a traumatic event will demonstrate normative stress response symptoms that must be supported to minimize the long-lasting and even more detrimental psychological effects. 


\section{Importance of Research}

Prevalence. Emergency events come in many shapes and sizes, frequent types of events include: motor vehicle accidents, violence, home fires, natural or manmade disasters, and medical emergencies. In most communities, more than $2 / 3$ of children report experiencing an event as traumatic by the age of 16 . In 2006, 7.9 million children received emergency medical care for unintentional injuries (e.g., motor vehicle crashes, falls, fires, dog bites, near drownings) (APA, 2008). More often than not, children are exposed to multiple events that are traumatic, with each subsequent event making the child more vulnerable to its psychological consequences (APA, 2008). In addition, to these emergencies that directly impacted children, there are countless other events that indirectly involved children. A large proportion of the deceased and injured likely have children who are greatly impacted by their death and/or injury despite their lack of presence on the scene of an emergency. Furthermore, siblings and peers can also be greatly impacted by emergency events despite their lack of direct involvement. According to Missouri Department of Transportation's latest car accident statistics report (2013-2015), in --- city there were a total of 130 fatal car accidents and 620 car accidents with serious injuries (MoDOT, 2013). Approximately every 47 hours a homicide takes place, for a total of 187 homicides occurring in --- in the year 2016 (Metropolitan Police Department, 2016). Given the amount of trauma potentially impacting children and the limited scholarly attention to the systems of care in place, understanding this phenomenon is of critical importance.

Impact. It is normal and expected that children demonstrate distress after experiencing an emergency event. Typical symptoms might include an increase in 
clinginess to caregivers and loved ones, sadness, sleep disturbance, somatic symptoms (stomachaches and headaches), irritability, and problems with school work and concentration (Osofsky, 2011). However, if these symptoms of distress are prolonged and normal functioning does not resume after a short period (several weeks to months), further concern for more severe psychological impact occurs, including potential for anxiety, depression, and post-traumatic stress symptoms and disorders (Osofsky, 2011). Studies have indicated prevalence rates as high as $30-40 \%$ for anxiety, depression, and /or post-traumatic stress disorder for children affected by disasters (Bonanno, Brewin, Kaniasty, \& Greca, 2010; Pfefferbaum, Jacobs, Griffin, et al., 2015b).

Further, when children experience stress, the body activates the biological stress response system, empowering the child to survive by utilizing a "fight, flight or freeze" reaction. Stress chemicals increase, the body's sensory systems which become hyper-alert (searching for further threat), and more complex thought processes come to a halt (Perry, 2009). It is when the biological stress response system is not relieved, but remains vigilant and in overdrive, that children experience detrimental developmental setbacks that can last a lifetime (Perry, 2008). The Adverse Childhood Experience (ACE) study was among the first to reveal this grave reality (Felitti et al., 1998)

Adverse Childhood Experiences. Perhaps, the most alarming understanding of how traumatic events negatively affect children, adults, and society as a whole can be found through the study of Adverse Childhood Experiences (ACEs). Adverse Childhood Experiences are stressful or potentially traumatic events that happen during childhood that can have lasting effects on health and well-being (Perry, 2009). The types of trauma ACE studies measure most frequently include: physical abuse and neglect, verbal abuse, 
sexual abuse, emotional neglect, family alcoholism, domestic violence, incarceration, mental illness within the family, and divorce, death, or abandonment by a caregiver (Kalmakis \& Chandler, 2015). The scientific study of ACEs has revealed five important facts regarding the impact of childhood trauma on the person, their health, and society as a whole (Kalmakis \& Chandler, 2015; Van Der Kolk, 2005): a) most people have at least one ACE; b) ACEs damage the function and structures of the brain; c) ACEs impact nearly every part of the body causing short and long-term health consequences throughout life; d) ACEs can alter our DNA functions and these alterations can be passed down through generations; and e) the brain has great plasticity and the body wants to heal.

When children experience traumatic events, especially multiple traumatic events causing them toxic stress, their cognitive functioning is altered, and their coping becomes impaired leading them to establish negative coping techniques (e.g., substance use). These unhealthy coping mechanisms then contribute to disease, disability, social problems, and in extreme cases premature mortality (Felitti et al., 1998). Research indicates there is a dose-response relationship between ACEs and later health problems. Children with higher ACE scores, or increased levels of exposure to traumatic events, experience increased intensity and amount of negative health outcomes (Felitti, 2009; Gilbert et al., 2015). Sacks, Murphey, \& Moore (2014) using data from the National Survey of Children's Health (NSCH) conducted in 2011/12 by the National Center for Health Statistics, found that $46 \%$ of children from birth to age 17 living in the United States have experienced at least one ACE. In Missouri, 35\% of children have experienced one or two ACEs and $12 \%$ three or more. The most common type of ACE reported in 
Missouri was economic hardship, followed by divorce, alcohol and mental illness, and violence. Fortunately, the brain has great plasticity in childhood and given the appropriate support, at the appropriate time, many of these disastrous effects of childhood trauma can be avoided and/or healed (Perry, 2006). Understanding the depth and breadth to which traumatic events can impact children throughout life and society as a whole is essential to recognizing the necessity of this study.

\section{Trauma-Informed Care \& Psychological First Aid}

Trauma-informed care is a treatment framework that involves understanding, recognizing, and responding to the effects of all types of trauma. Trauma-informed care recognizes the physical, psychological and emotional safety needed for both providers of care and survivors of trauma and helps to rebuild a sense of control and empowerment (Steele, 2009). In 2007, a group of clinical experts from around the world met with support of the NIMH Traumatic Stress Research Program and the Substance Abuse and Mental Health Service Administration to discuss the essential elements of immediate and midterm mass trauma interventions. This meeting resulted in five key elements which include: a) promoting a sense of safety; b) promoting calming; c) promoting a sense of self and community efficacy; d) promoting connectedness; and e) instilling hope (Hobfoll et al., 2007). Psychological First Aid (PFA) is an evidence and trauma-informed care approach that utilizes these five key elements and is effective in reducing distress, fostering short- and long-term adaptive functioning, and linking survivors with additional services in the acute aftermath of a traumatic event (Vernberg et al., 2008). The major elements of psychological first aid include: establishing contact, addressing basic needs, protecting from further harm, listening and gathering information related to mental health 
needs and psychosocial concerns, providing reassurance and education, responding to distress and psychological symptoms, assisting with coping and problem solving, and connecting the individual with support systems and formal services if needed (North \& Pfefferbaum, 2013).

Much of the theoretical basis for PFA comes from Abraham Maslow's theory of human motivation (1943) or hierarchy of needs. Maslow (1943) described a series of hierarchical needs that must be met, in order: a) physiological needs (e.g., food, water, shelter); b) safety needs (e.g., helping survivors avoid subsequent danger and establish emotional and psychological safety); c) belongingness and love (listening, encouraging survivors to reconnect with positive social supports); d) esteem needs (prestige and feelings of accomplishment - not actually addressed with PFA); and e) self-actualization (achieving one's full potential - not actually addressed with PFA) (Halpern \& Vermeulen, 2017). The model of psychosocial response utilizes these scholars, PFA, and Maslow's theory of human motivation in understanding the needs of children after experiencing a potentially traumatic event and providing a system of care delivery that supports those needs.

\section{Previous Research involving First Responders}

Research on first responders' experiences during traumatic emergency events have generally focused on their personal psychological health and well-being and professional quality of life (Kleim \& Westphal, 2011; Stamm, 2002). First responders are exposed to stressful and traumatic situations multiple times on a daily basis. Most often

they are the first ones on the scene of a traumatic event, they are immediately exposed to the raw sensory experience of violence, injury, and death. Significant predictors of first 
responders' physical and mental health outcomes include event-specific factors (e.g., proximity, duration, intensity of exposure, perception of personal threat) and contextual factors (e.g., previous traumatic experiences, subsequent experiences, social and interpersonal events) (Benedek, Fullerton, \& Ursano, 2007). Prevalence rates for PTSD among first responders have consistently demonstrated higher rates than general populations (Jones, 2017). For firefighters and paramedics, PTSD rates have ranged from 7-68\% and for depression to range from 3-21\% (Jones, 2017, p. 201; Kleim \& Westphal, 2011). For police officers, who often encounter violent situations, PTSD rates have ranged between 7-19\% (Bowler et al., 2010; Ellrich \& Baier, 2017; Maguen et al., 2009). Norris et al. (2002), in a large review of 60,000 disaster victims, found that one in every eight disaster responders developed severe to very severe impairment in mental wellbeing.

Not all psychological outcomes of first responders' work are negative, positive psychological sequelae also exist. Post-traumatic growth (PTG) refers to these positive psychological changes that emerge as a result of enduring a traumatic event (Tedeschi \& Calhoun, 1996). Such changes may include: a sense of personal strength, a deeper appreciation for life, closer relationships, new possibilities, and a richer understanding of spiritual matters (Roepke, 2015). Post-traumatic growth has been studied and identified in direct trauma survivors (Arpawong et al., 2016; Roepke, 2015) and in first responders (Shakespeare-Finch, Smith, Gow, Embelton, \& Baird, 2003). Shakespeare-Finch et al. (2003) conducted a cross-sectional investigation of positive changes in emergency ambulance personnel who often participate in traumatic events as part of their work duties. Results indicated that $98.6 \%$ of participants perceived they had experienced at 
least one positive change following a work-related traumatic event. Changes experienced most often included perception of his/her own strength and a renewed appreciation for life and relationships with others. Similarly, Stamm (2010) defined compassion satisfaction as the benefits individuals derive and pleasure they receive from helping others who are traumatized or suffering. Those who experience compassion satisfaction typically have positive thoughts about the work they do and feel effective in making a difference to individuals and the community (Stamm, 2010). Importantly, prevalence rates for negative psychological sequelae tend to be less for trained first responders when compared to volunteer first responders (Perrin et al., 2007). This indicates that training may have an important influence on how first responders cope with their daily work in traumatic situations.

To this author's knowledge, no researchers have inquired about first responders' specific experiences working with children to date. A few studies have resulted in specific findings about first responders work with children. One study investigated police officers' perceptions of stress-inducing events in the workplace and found that police officers often experienced feelings of powerlessness and despair when responding to events involving injuries or fatalities of children (Karlsson \& Christianson, 2003). Ursano $\&$ McCarroll (1990) found that first responders and disaster relief workers who were tasked with handling dead bodies, identified children's dead bodies as particularly stressful. Further, workers attributed this stress to the children's "innocence, untimely death, and appearance of complete victimization" (Ursano \& McCarroll, 1990). Many concluded that their ability to familiarize with the children and the parents of the deceased children made it especially challenging. 
Because firefighters are often the first people on the scene, they are in an optimal position to administer PFA and decrease continued trauma exposure however, their perception of their duty to provide this service and logistical capability to do so is largely unknown. The focus of the present investigation is the current emergency response system of support for children and its efficacy in providing trauma-informed support during traumatic emergency events. By analyzing the lived experiences of first responders during these events, a systematic model for support services can be informed. The long-term goal of this research is to decrease traumatic effects of emergency events on children by providing evidence-based, systematic trauma-informed care in the acute aftermath of emergency events. 


\section{Chapter 2: Research Aims and Questions}

AIM 1: To understand firefighters' lived experiences of children's reactions to emergency events.

RQ1. What do firefighters experience as children's reactions to emergency events?

AIM 2: To investigate the current system of trauma-informed care provided to children in the acute phase of emergency events.

RQ2. How do firefighters identify their role in the psychological and emotional care of children during emergency events?

RQ3. What are the current systems providing children with emotional support during and immediately following emergency events?

RQ4. What are the gaps in services and how can those gaps be filled? 


\section{Chapter 3: Methods}

Porter's (1998) descriptive phenomenological approach was utilized to gain insight into the current emergency response system of support for children and its efficacy in providing trauma-informed support during emergency events. This method focuses on each participant's intentionality and context of their experiences and is largely based on the early phenomenological methodology of Husserl (Husserl, 1962; Porter \& Cohen, 2012).

This descriptive phenomenological approach was carefully chosen with first responder organizational culture in mind. Culture refers to the unique identity that defines one group or community from another (Stinchcomb \& Ordaz, 2007). First responders are an extremely tight-knit community. Living in tight quarters, relying on each other in dangerous situations, and shared experiences in service creates a community that is often referred to as "family" (Woody, 2005). First responders also have a reputation for being closed off to mental health services and sharing of their experiences to outsiders. This largely relates to fears of occupational efficacy being questioned and being observed as "weak", and a desire to protect lay persons from traumatic exposure (Kupersanin, 2002). For these reasons, first responders often process their work related traumatic exposures and receive support from close colleagues who have had like experiences (Stinchcomb \& Ordaz, 2007). It is important that research is conducted in a manner that builds trust and allows first responders to share their experiences at their own pace. This descriptive phenomenological approach allows multiple interviews to take place in the first responders' work place environment, increasing the ability for first responders to gain trust with the researcher and to utilize their environment to help share their lived 
experiences. The focus of the interviews was on sufficiently gaining insight into his/her experiences of being a first responder and working with children during emergency events to enable informed comparison of other participants' experiences in the same phenomenon (Porter \& Cohen, 2012).

By understanding the collective experiences of these first responders involved with children and using those experiences to inform a model of trauma-informed care, supportive systems of service delivery can be developed to meet the needs of children with the goal of minimizing trauma and promoting resilience. In addition, this phenomenological approach enables the researcher to gain a deeper understanding of emergency response systems already in place that can best inform trauma-informed systems of care in the future.

\section{Participants}

Purposive convenience sampling was utilized to describe participants' common experiences (Creswell, 2013). For the purpose of maintaining a description of similar experiences, inclusion criteria was set to include first responders who serve in the --- City Fire Department who have worked with children in emergency events. Phenomenology requires that essential structures and meanings of a lived experience be obtained through knowledge from individuals who have experienced it, thus first responders who have not had experiences with children in traumatic events were excluded (Husserl, 1962). Having a sample concisely serving within --- City increased the likelihood of common experiences due to similar support systems, training, and organizational structures.

The researcher first contacted first responders in the --- region with whom the researcher already had a personal connection and explained the researcher's interest. The 
researcher then requested information regarding the chain of command processes for research approval and followed that chain of command. The researcher then obtained a signed permission letter from the appropriate personnel, obtaining permission to seek first responders under his/her command for research participation. Once permission was obtained, the researcher requested to visit with the known first responder in his/her place of work to initiate building rapport amongst his/her colleagues. During that initial visit, the researcher informed first responders about research and sought level of interest among colleagues, gathering contact information (phone, email) for those interested in participating. The researcher then sought additional first responders to interview through word-of-mouth using the snowball sampling method. The snowball sampling method will enable the researcher to receive participants from first responders speaking with other first responders who have had significant experiences with children during emergency responses. This method allowed the researcher to access participants who were information-rich (Patton, 2002).

A total of eight male first responders participated in the study. All eight held the role of firefighter and had also been trained EMT/paramedics as well. Their overall first responder years of experience ranged from 3-20 years, and their years in their current role at the time of the interview ranged from 2-11 years. First responders initially were located in two separate firehouses (4:4), however, at the time of second interviews a first responder from each site was transferred to a different firehouse; making the total number of sites visited four.

\section{Procedures and Data Collection}


After campus IRB approval, leadership permission amongst emergency

management systems, and informed consent was obtained, the researcher contacted the known first responder by phone to setup the initial on-site visit and potential interview. The initial on-site visits consisted of a tour of their work place and several hours of building rapport with the known first responder and others on their team present at that time. Initial interviews took place with those first responders willing during the later half of this first visit; subsequent interviews took place on later dates. Each visit consisted of time spent in the first responders' place of work, casually building rapport, prior to initiating any interview.

Data was collected from a total of eight different first responders by means of semi-structured interviews with the first author, each lasting approximately 20-50 minutes. Initial and second interviews all took place at the first responders' designated firehouse, except for one second interview that took place at a public library in a private room.

Semi-structured interviews were conducted to encourage participants to share their lived experiences and discourage the influence of the researchers preconceived notions about the phenomenon (Porter, 1998). The first question will be broad, asking first responders to describe a time that they responded to an event and children were involved. This will allow first responders to drive the interview and the researcher to use follow-up probes to elicit more details about their lived experiences.

In line with descriptive phenomenological methodology, data were collected throughout the research process from environmental observations and semi-structured 
interviews, both collected during on-site visits (Porter \& Cohen, 2012). Field notes were taken on a small notebook during both the on-site visits and the interviews.

First responder work place culture does not always encourage the expression of feelings or seeking mental health support (Kronenberg et al., 2008). It was important for the researcher to let the first responder lead the interviews at his own pace and comfort level. The researcher utilized paraphrasing and validation throughout the interview to build rapport and trust with each participant. Additionally, it was important to recognize that qualitative research interviews are often therapeutic in nature as they offer a safe space for sharing their stories and meaning-making (Rossetto, 2014). Vulnerable populations in the past have also revealed that qualitative interview participants experience research as positive and beneficial to both themselves and others (Cook \& Bosley, 1995); thus, supporting a therapeutic impact of research participation rather than a traumatic one.

Debriefing was completed after each interview and focused on bringing the participant back to a positive and safe place mentally and emotionally. Positive affirmation for a job well done and asking them to reflect on what they enjoyed most about their jobs were common methods utilized. Finally, a handout providing additional resources for first responders dealing with secondary trauma was offered and provided, including confidential mental health resources available. Importantly, none of the first responders interviewed expressed a desire to receive the handout.

Several steps were taken to ensure that this research was trustworthy, credible, and rigorous. First, methods and research procedures were explicitly outlined prior to engaging in data collection. Second, interview protocols were reviewed by experts both 
within and outside the field to minimize bias by the first author. In addition, second interviews focused on gathering more information and probing on data collected during first interviews; unique and common experiences identified by participants in first interviews were clarified and asked among all participants during second interviews, utilizing member checking throughout the research process. The author also kept a reflexive journal documenting her own experience with the phenomenon prior to engaging in the research and throughout the entire research process. This journal served as a collection of self-reflexivity documenting breakthroughs, thoughts, and observations made, acknowledging the interplay between the researcher's positionality and the participants' experiences of the phenomenon (Yin, 2011). 


\section{Chapter 4: Data Analysis}

Interviews were transcribed verbatim by the author, undergraduate research assistants, and other trained professionals and checked for accuracy by a second transcriber. After transcription was complete, utilizing Microsoft Word, transcripts were converted to a table format to assist in the data analysis process. Next, in accordance with Porter's descriptive phenomenological methods, the author reviewed the data for ideas that were irrelevant, part of the life-experience or phenomenon of interest, and those part of the life-world context to create units of analysis (Porter, 1998). Each were distinguished using varied formatting techniques. Irrelevant data, those units not related to the first responders' experiences working with children in emergency situations, were distinguished and not included in the analysis.

Life-world contextual units were marked using the reference marking citation and table of codes tools in Microsoft Word, capturing ideas related to the reality of the phenomenon that is typically taken for granted, often influenced by social norms (Porter \& Cohen, 2012). Using Porter (1995) guidelines, life-world units were then extracted into a separate table and subcategorized into elements (most specific), descriptors (groups of elements), and features (broadest level of life-world units of analysis). For example, when participants described children's reactions during emergency events, groups of elements (e.g., "a lot of them were just emotionless...like they've seen this before" and “some kids don't seem to react to much... it seems like their normally used to it.") were grouped together and given a descriptor (e.g., "unphased" or "going about their business"). Descriptors were then compared and contrasted, similar descriptors were 
then grouped into features, the broadest level of the life-world context (e.g., "lack of reactions").

Similarly, life-experience data was distinguished using the reference marking citation and table of codes tools in Microsoft Word, color coded in relation to specific research questions they addressed, then extracted using a separate table to further classify into three levels: intentions, component phenomena, and phenomena (Porter, 1998). Intentions are the ways in which respondents understand and shape their experiences. Intentions were discerned by describing, comparing, distinguishing, and inferring from the data continuously evaluating, "what is the first responder wanting to do in this experience?" (Husserl, 1962). Intentions were captured using quotes that represent commonalities among first responders. Component phenomena represent patterns of intentions that emerge from multiple participants by comparing and contrasting interviews with first responders and other data collected and assessing them for similarities and differences. Lastly, at the broadest level, phenomena were extracted from the data. Phenomena represent general patterns of component phenomena (Porter \& Cohen, 2012). For example, when participants referred to their role in supporting children on the scenes of emergency events, groups of intentions with commonalities (e.g., "they were scooted out of the room pretty quickly" and "let's get the kids out of here... we kind of scooted them out.") were grouped together as component phenomenon (e.g., "scooting out" or "diversional conversation"). Component phenomenon were then compared and contrasted, similar ones were then grouped into phenomena, the broadest level of the lifeexperience (e.g., “distraction”). 
Throughout the entire data analysis, features and phenomena were continuously discussed with first responders during subsequent interviews to confirm accurate representations of their experiences (Yin, 2011). Participants' own words were used to describe features and phenomena. 


\section{Chapter 5: Results}

Findings represent similarities surrounding first responders' experiences with children during emergency events within social contexts (life-world) and ways in which they responded based on their own experiences (life-experiences). Four distinct research questions were included in this study: 1) What do first responders experience as children's reactions to emergency events? 2) How do first responders identify their role in the emotional care of children during emergency events? 3) What are the current systems providing children with emotional support during and immediately following emergency events? 4)What are the gaps in services and how can those gaps be filled? First responders revealed several features and phenomena each are presented below utilizing direct quotations from first responders.

\section{Life-World Context}

Differences between north and south city. It became clear during on-site visits and interviews that there were two distinct areas of this city - the north side and the south side. First responders described the south side of the city as more "well off," apartment living that was "\$2,000 a month" for rent, "mansions and million-dollar incomes." First responders were interviewed from both areas, and in each area first responders consistently described this divide in the city. First responders described the north side as an impoverished population, high on violence and drugs, short of resources, and living in a state of static trauma. One first responder working on the north side asserted, "I've seen in three years working for --- city, I've patched more bullet holes and seen more people shot...than an entire 20-year career in the military; where I wasn't like, military where you kind of hang out on base...I did a lot of stuff with Special Operations...where 
kids are running around carrying guns and shooting at each other...where that's all I did...was supposed to do...create bullet holes or patch bullet holes." As an emphasis to this description, first responders consistently walked the researcher to and from her car, made sure she was not still on site once it got dark, and created a safety plan each time she visited should they all need to respond at the same time to an event, leaving her alone in the firehouse. Another first responder described this area of the city as, "it's a completely different world...most...of us have never known...me, at ten-years-old, could never have imagined living in a house that's falling apart, there's no heat, no food, trash piled to the ceilings, bugs and stuff all over the walls. I just can't imagine... It's the norm here." Another firefighter described responding to a call for an apartment fire and upon arrival, they found an immobile caregiver in one room, with further investigation they then found around six kids in the back bedroom, "I went in the room, and these kids, it was clear they hadn't been bathed, they hadn't had diaper changes, and they had dog food in the bed, and it was what they were eating... we called the police...the police were literally taking wet wipes to clean the kids because they hadn't been bathed...I think they also found a rag to wrap as a diaper." This divide in the city became important context when understanding first responder differences in their experiences with children during emergency events. This first became apparent when they discussed children's reactions during these events.

First responders' experiences of children's reactions. Each first responder described a variety of reactions from children on the scenes of emergency events either as survivors of the event themselves or as bystanders. These reactions varied greatly from 
situation to situation, however, four phenomena were extracted from their collective experiences.

Lack of reactions. First responders often described an absence of reactions from children on the scene of emergency events. One firefighter described the children on the scene of a parental drug overdose as, "going about their own business... sucked into their video game... may not have noticed anyone else was even in the house." Another firefighter described in general that, "most kids don't seem to react much to things going on. It seems like they're normally used to it. It's like we aren't even there...more often than not they won't even look up at us off the TV. It's just not even interesting." During a response to care for a mother who was having difficulty breathing, another firefighter described six children, ages 1-10 years old as being in the house, and their reactions as "they really didn't seem phased by the fact that there were other people in the house or emergency responders, or that we were taking her mom to the hospital, or anything."

Emotion-based reactions. Not surprisingly, first responders also discussed common emotional reactions from children in emergency situations. Crying, worrying, screaming, anger, sadness, guilt were all mentioned numerous times. One firefighter described a child's reactions during an accidental shooting, "the child that pulled the trigger, I just remember him crying and like, you know saying he was sorry and it was, that wasn't what he meant to do...just uncontrolled weeping...shaking...just overload with adrenaline...just emotion.” Another firefighter described responding to an emergency event in which brothers were wrestling and one put the other on a rusty fence post, which then ripped his leg open. The firefighter described the sibling responsible as 
"telling his little brother 'I'm sorry'...'don't die"” and as being "in a huge worry frenzy...panic, cry, scream.”

Information-seeking reactions. Other reactions from children discussed from first responders, included children seeking answers and information related to what was happening and the status of their loved one(s). In describing a medical response to a mother in serious condition with two children present in the home, the first responder stated the "kids were very inquisitive of what was going on with mom...one of our guys was taking care of mom and the other guy was telling the kids what was going on, and that we were going to take care of their mom, and answering their questions and stuff like that." Another first responder discussed a car accident in which a mother was driving, and three kids were in the back seat. Upon arrival the mother was dead, and two of the three kids were still conscious and stable, "the little girl asked me...not even asked me, basically told me, you know, is my mom dead?"

Observant reactions. Other times firefighters described children as observing the situation from either near or far. One firefighter generally described this phenomenon, "kids were all just kind of standing around watching. Not much to say." Similarly, another firefighter described arriving to a heroin overdose scene and the "kids are just sitting around watching it like it's Sesame Street or something."

Results also revealed that these reactions were experienced disproportionately in each area of the city. For example, one first responder described children's reactions to an event on the north side, "me, as a ten-year-old could have never...fathomed someone on my street getting shot, let alone seeing it happen multiple times throughout the summer...could never have thought about or fathomed having a friend who's been 
shot...so stepping into that situation you've got to almost be aware...this isn't the thing I'm used to...I mean you can sit there and tell a child ok...this is going to be alright...when in reality they could really give two shits less...because they're like 'so and so got shot! I've seen people shot before you know' so you got to approach it differently." First responders also described this area of the city as having more children out and about unsupervised, "and the environment we work in, lots of times the groups of kids are kind of free roaming... even with something like that going on, the parents won't come check on the groups of kids, they just kind of let them be." They described how when they would respond to an event, it was common to have kids just watching in packs on the outskirts, one first responder in discussing a response to a drug overdose, stated upon their arrival, there was "probably 10,11,12 kids there... all just kind of gathered around watching." Another first responder stated, "If you are in a poorer place, you're gonna interact with it [first responders] more, more likely than not because the first responders are more present in their lives, for just general sickness, illness...it's just a side effect of where they live... whereas if you go to a higher income neighborhood, you're interacting with them still, but it's almost differently...you don't have as much face one-on-one interaction and they don't deal with someone's coming to pick up my mother or my little brother...there's a big difference and I think that's a major contributor."

\section{Life-Experience}

First responders' roles in the emotional care of children. When first responders were asked to identify their role with children on the scenes of emergencies, all emphasized their number one priority as patient medical care and scene safety, 
"situation mitigation... whatever the situation is, to solve it...the top priority is life safety." Another first responder said, "we got to make sure the scene's safe...make sure the patients are safe...it all depends on what we come up on." Several first responders individually described the same emergency response to a motor vehicle accident on an exit ramp involving four fatalities and six ejected victims. Each of them described their steps in treating the victims, which included five children, four whom were all unconscious. When the researcher inquired about this fifth child's emotional response or involvement on the scene, none of the first responders recalled any details about how this child was responding or whom was with this child while they were providing patient medical care, "I don't remember anything about that one." They each emphasized in various ways that in large critical scenes, such as that, "when you have.... person in that critical need and...chaos brewing... you gotta stay pretty focused on what's in front of you."

Despite their number one priority being patient medical care, all first responders also described how they supported children, when able, using a variety of techniques and skill sets. Most of the time, these supportive roles were described not through direct interview questions, but through first responders sharing instances in which they responded to emergency events involving children. Three phenomena became clear in regard to how first responders identified their role in supporting children emotionally on the scene.

Distraction. First responders often utilized distraction as a method to support children on the scenes of emergencies. They discussed using conversation, a TV show or movie, giving them tours of the fire truck, and assigning roles to the children as common 
modes of distraction utilized on the scenes. One firefighter discussed how he tries to "take their mind off of it...talk to them about school... a favorite show...redirect their thoughts of the bad stuff that's happened." Another first responder described how he tried to "take the kids out, and let them see the truck, play with the lights and stuff." Others described how mode of distraction depended on the situation and if the kids were comfortable separating from the victim/their loved one or not, "It just depends on the situation. Or you keep them busy. Give them a task that they believe might be important. Tell them to get something... you tell them that you might need a blanket. If they get you a blanket, tell them to get you a pillow... keep them busy, move them around."

Calming and reassurance. Many times, first responders discussed how they try to calm kids down on the scene of emergency events by providing reassurance. They discussed how if they are confident things are going to be okay, they try to let children know that. But if they are not sure, they often will give simple information, "but not a conclusion...we are going to take them to the hospital immediately...we are doing this...we're helping..." One firefighter described how he tries to calm and reassure children, "I always kneel down next to them, and 'hey listen. I promise we are going to take very good care of her. Your mom's sick, but we're going to take good care of her. We'll bring her back here to you. She's going to feel much better.'”

Education. First responders often described helping children to understand what was going on and answering their questions as a way of providing support to children during emergency events. One first responder described how he tries to, "get them to understand a little bit better what's going on." Another first responder, described "telling the kids what was going on and that we were going to take care of their mom, and 
answering their questions..." Another fire fighter described avoiding answering more difficult questions posed, specifically during a response to a fatal car accident involving three children and two adults. After extricating the survivors out of the car "the little girl asked me...' is my mom dead?'...you know, what do you say to that? Especially you can tell she knows...it's not like the little kids who you can distract them from that...she's old enough to know what was going on...I knew the answer to the question. I would avoid answering it if it was an adult asking, let alone a kid."

Although, not part of my research questions, it became clear that first responder emotional reactions are important to consider in these situations as well. One first responder described, "my heart was breaking for the kids...I wish I could just adopt these kids...it's hard for me to realize that is wasn't an isolated event... which was pretty upsetting." Another fire fighter described arriving to a call for a three-year-old who was unconscious and barely had a pulse, "the kid had been down for so long, he was pretty much brain dead...the worst part about that call was that were probably about 11 people in that house and nobody knew what happened to this kid...that still upsets me because we come to find out the kid ended up dying."

Current systems of support. When first responders were asked to describe emergency events involving children, organically, several systems of support for children were described. Further, when the researcher asked specifically about what resources or systems of support were available to help support children involved in these emergencies, several phenomena became clear - family members, neighbors, police officers, and hospital staff. In the case that neighbors were not alerted with lights and sirens, first responders described, "we have to ask if there's a neighbor...another family member...if 
they're not there, usually we have to get...the police involved." Most often these systems of support and their accessibility revolved around proximity to the emergency scene and the medical care necessary.

Family members. Interestingly, family members were not mentioned often as supporting children on the scene. First responders often discussed family members as being wrapped up into the situation and forgetting children were also present. One firefighter described a medical response in which the grandmother was in cardiac arrest and they were dong CPR, "the kids were just standing in the doorway, and our captain had to say, 'hey...lets get these kids out of here'...you know, we kind of scooted them out, and told the mom, 'the kids don't need to see this." Another firefighter described responding to a shooting in the middle of the street in which the victim's "head is just blown apart" described the child bystanders present watching along with their parents, "and these people, their kids were all around the front porches. Just staring at this, ya know, they witnessed the whole thing. Like in that... I still think about that, and it's like, ya know, I know crime is everywhere. Ya know, murder is everywhere... but I couldn't imagine, me as a parent, sitting there, allowing my kids...to stare at this." First responders also identified family members as key support members whom they needed to get in contact with if a caregiver was the patient needing to go to the hospital and the children present on the scene could not be left alone, "so if there is a responsible neighbor that like usually babysits the kids...they can go to the neighbor's house.... a family member who is a distance away that is less than the time we are getting ready to leave with the patient also is called." 
Neighbors. Neighbors were most often mentioned as those whom provided support to children, not medically in need, on the scenes of emergencies when family was not present. First responders often described their arrival on scene with lights and sirens, naturally bringing neighbors out of their houses, if they weren't already out, and typically these neighbors were first to hug and support the children present. One first responder described responding to a quadruple shooting from a drug deal gone wrong in which two children were present in the car with their parents both dead in the front seat, "so when we pulled up there, I mean we could hear her...she [the youngest girl] was on the porch, and she kept saying 'they shot me, they shot me in the head!'...one of the neighbors maybe got her out because...that's when the neighbors kind of grabbed her and put towels on her head."

Police officers. In describing support for children on the scene, firefighters had different experiences with how often police officers were involved. One firefighter described, 'I don't know the police's involvement in that because they're so short staffed that if...if the kids are in harm...if we walk in and can identify that these kids are in immediate harm then we'll get the police involved, but if...if it is just a person going to the hospital with kids... usually the hospital just kind of handles it...in a municipality where the police have more resources and more time to deal with things...I think that probably is something that we used to do, the police would come, but that was then, this is now." Another firefighter described, "if there's a child and there's any kind of injury, often the police will respond." During an on-site visit with several participants in conversation, the group of firefighters discussed with the researcher how as firefighters their time on scene is often shortest, they come in, stabilize the situation, then get as 
quickly to the hospital as possible. Whereas the police officers arrive and often are there much longer, taking reports, connecting with caregivers who can stay with children or the Division of Family Services if needed. This was later emphasized during an interview, “we don't have a lot of time with people...I'd say more often than not, a police officer will end up with a kid.”

Regarding police officers, firefighters also discussed the community's receptiveness to police officers as being somewhat of a barrier to their effective support to children during emergency events. Firefighters described the community's perception and overall trust as being vastly different between the fire and police departments, "the public in general trusts the fire department... we kind of have the reputation of always being the good guys. Always being there to help and nothing but that, so we've gained the public's trust, and the parents relay that to the children." Another firefighter stated, "the police obviously have interaction with children and interaction with the family and I feel like the police are trying their hardest with the culture that is here...I feel like a lot of the parents and a lot of the siblings...just everybody makes the cops out to be the bad guys...it makes it really hard for the kids ...to see anything...but the bad guys when cops show up...so, like I think the police try really hard.” Another fire fighter described this same phenomenon, "Well, this day and age, like, lets, for example, if like the police, everybody's scared of the police, you know, these kids are raised to, you know, 'cops gonna shoot me, if they show up,' you know, that's, that usually adds a little bit to the chaos but, you know, a lot of these cops, they're really good with kids too and they know how to handle it, you now, and they kinda know the lingo and they can escort them off..." 
Hospital staff. One last phenomenon identified by firefighters in this study in relation to the current systems of support for children during emergency events included hospital personnel and staff, specifically "social service types." Firefighters described that many times the goal is to get to the hospital as quick as possible, so time for emotional support is limited. They discussed how they felt comfort in knowing that once they got to the hospital they knew an abundance of resources and support for the children and family would be available. One firefighter, described a field ethical dilemma with regard to pronouncing death on the scene versus waiting until one is transferred to the hospital, "Well, some people would say that you should pronounce them dead, 'cuz we have that capability and some protocols to do so...then let the process that would happen, happen. Uh, my personal belief on that...is the other side of the spectrum, is that regardless, as long as it's not a crime scene, take them to the hospital, go through the process...not to create false hope, because that's the people that say you shouldn't do that say you're creating false hope for the parents, and that's absolutely not the case...the one thing I know the hospital has support staff...that's where...if something comes up, we rely heavily on the hospital support staff for doing that." Another firefighter described the support available at hospitals, "when we get to...the children's hospitals, man they are so good, there are so many... social services types that are there right away...you know you go into the trauma room, there's doctors and nurses and techs. And everyone doing the medical side...the behavioral adaptive side...all those people are in the hallway....and there's not one or two, there's a lot..."

Gaps in services. Firefighters were asked to describe what would have been helpful or what resources they dream about when thinking about children on the scenes of 
emergency events. Two phenomena identified included specialized and dedicated support and effective first responder training.

Specialized and dedicated support. Numerous times firefighters described situations in which specialized and dedicated support for children was lacking. Specifically, during critical situations when medical care took priority, first responders often discussed being unable to identify whom/if anyone was supporting the children who were less critical or bystanders to the incident, "I really don't remember just the bystanders of situations. I don't necessarily have tunnel vision, but those things go out of my head pretty fast. I remember the patients, never, not necessarily ever the scenes." Other times, first responders described caregivers or neighbors as being oblivious to the children needing support, "...the family is concerned about the patient, who is in distress or critically injured...not realizing there is a three-year-old over their shoulder watching." An example of the specialized and dedicated support desired by first responders was described as, "what I want is a social worker in the car following us to the call...someone... who specializes in taking care of kids to help them right away. Not when they get to the hospital, right away...a little police car looking thing driving behind the fire truck, it would be great!" Another firefighter said that, "I think if there was already a social worker...someone else there with us, it would just be better."

Effective first responder training. Most of the firefighters included in this study described feeling somewhat confident with how to support children on the scene. When the researcher inquired how these skills were gained, all described learning these skills either organically on the job by modeling more experienced first responders, "You kind of zone in on, gosh, that looks horrible, I don't know what I would say there...but then 
you're also observing and picking up on okay that's how, that's how to do it and then you put it in your pocket of tools..." or by previous experiences with children (either their own or in other settings). One firefighter described both gaining these skills through mimicking others in the field and how having children as first responders helps, 'I'm sure in a chapter in a book in this room somewhere...it comes down to personality, and which I did not have. Bedside manner, that's what it comes down to, which I did not have. I had to look at other successful people and what they were doing, mimic them and what they were doing and then...then having kids. You know...the guys that have kids...having kids helps." Another firefighter described his knowledge of working with children during emergencies coming from his previous experience working at a children's hospital for six years, "Most of it's just been from...I guess from Children's, learning it there, and bringing it out to the street...I had it down pat...I knew how to do it." Of those firefighters in this group, none described formal training being effective in teaching them these skill sets, "there's no, I mean...they talk about it in EMT school, like those stages of stuff like that...they don't teach you how to look at them and understand what's going on. You know, there's a little bit, but not enough." One firefighter even pulled a book off the shelf in the interview room that had a chapter on working with children but described its ineffectiveness in how that small chapter did not result in skills gained on the scenes with children. Some even described having not received any formal training regarding working with children aside from medical training, “As far as emotional support...I don't know if I've ever had a class or had anything offered to me specifically for emotional support on the scene...not for children anyways." 
Despite most firefighters in this study being confident working with children, several described colleagues not as skilled, earlier years in their own careers when they were not particularly skilled or lacked comfort with children, or specific scenarios that were more challenging with children.

When these first responders were further asked, what would help them gain this confidence and skill set, they described more experience and formal training. "Formal training would be extremely helpful...As far as focusing on children, in training one thing we need to...emphasize in training, we've gotta make sure that someone is there to focus on the children, whether it be someone designated -everybody needs to know that you have to have that focus there. A lot of times you'll go to a scene and for example, shootings: you've got one, even multiple shooting victims, everybody wants to go towards that. If it's one person with one bullet hole, you've got six people trying to help one person...obviously if there's ten people shot and there is five of you, you got to do what you gotta do. But, if there's the resources and personnel...then training needs to say 'hey, you've got to make sure one person has to take the children to the room...' Everybody wants to get in on the action a lot of time, and some of the people just forget about...they look at what is right there in front of them and they forget about everything that is surrounding..." Other fire fighters described the plethora of online-format classes they are "bombarded with" and how "personal classroom training" might be a more effective format to utilize.

Situations describing children asking more difficult questions, "is my mom dead?" or involving children with developmental delays. One first responder in describing responding to a scene where a mother tried to overdose to commit suicide and 
there was a young child with developmental delays, "you try to talk to her...she just looks at you with a blank stare...you try to do little tricks to kind of keep her happy... she didn't quite understand...I think we tried to pull out every rope that we could...every trick...between all of us, everybody tried." Another firefighter said in response to a child asking if her mother was dead, "and like all the blood and gore never has bothered me, but that, like I just...what the hell do you say?" When the interviewer asked what might have helped in these situations, while some said "nothing", others described having some better training on what to say and do in these situations, "training is always a good thing in general from people with different backgrounds...from people who know the path to take." When further prompted about what type of training would be most effective, first responders described training that was hands-on and specific.

When first responders were asked what resources would help these children involved in these emergency events, most often, firefighters in the north side described broad community-based resources such as more social workers and division of family services resources, better access to food, etc. One first responder discussed how, "a lot of those kids don't know that there's other opportunities out there...they idolize gang bangers...drug dealers...they idolize the people in their neighborhoods." He went on to say, “you know join the military...you don't see recruiting offices in north city...so a lot of those kids probably...don't know that there's other opportunities out there." Another fire fighter working on the north side responded "there's a lot of resources in this area specifically, being impoverished, that I think could be used, but you'd have to put a social worker in every residence... explain to the parents...you have the ability to give your kid a bed to sleep in...to feed your kids healthier food..." Whereas first responders working 
on the south side more often stated resources that would be directly relevant to working with children during emergency events, "stuffed animals...some departments have stickers...I can guarantee there's none in this engine house right now" or "we need to do a program of some sort...something almost to teach some of the guys how to deal with kids, like the redirection...breaking it down for them."

When first responders were asked how often they worked with children on the scenes of emergency events, their answers varied quite a bit. First responders across the city, even those within the same house described variance in how often they worked with children, "like three or four in the last few weeks" or "around thirty in a year" or "two this year that I can recall.” Many of them referred to their assigned truck (e.g. ladder truck, pumper, ambulance/medic unit) and their area of the city (e.g. downtown, residential) being the biggest difference makers, "EMS gets hundreds a year." Data was requested regarding rates of events responded to with children, however, was not accessible due to inadequate record keeping. During on-site visits, firefighters described the different uses for each type of truck, how they each are assigned in positions on each truck, and how they each are dispatched for different reasons. For instance, the "pumper" truck mainly carries water, but is smaller than the "ladder" truck, therefore, it responds often to medical calls rather than the ladder truck, which primarily responds to fires or elevated rescues. The EMS/ambulance and pumper were described as having the most calls and therefore those first responders assigned to positions on these trucks typically described having more interactions with children during emergency events than those on the ladder truck. Understanding the different roles within a fire house, helps to explain the differences in how often first responders might interact with children. 


\section{Chapter 6: Discussion}

This study was the first to examine the experiences of first responders during emergency events involving children. This study contributes empirical data as a basis for creating systematic trauma-informed interventions aimed at mitigating the short and longterm effects of these emergency events on children. Data analysis revealed several key findings in relation to how first responders' experience children's reactions, the roles first responders take on with children, the current systems of support, and the gaps in services described by first responders.

\section{First Responders' Experiences of Children's Reactions}

First responders described the reactions they observed most often from children on the scenes of emergency events as being a lack of reactions, emotion-based reactions, information-seeking reactions, and observant reactions. When first responders described children's reactions during emergency events, the city divide became an important context. While all reactions were noted in each area of the city, those working in the north side more often described the phenomena of children having a lack of reactions and observant reactions, whereas, those on the south side more often described emotion-based reactions and information-seeking reactions. This finding indicates that supportive services need to be adapted to individuals, especially taking into context their life experiences and own personal assessment of an event being traumatic. It is important to revisit the definition of trauma being self-assessed. A traumatic event is not defined by the type of event, but, rather, the combination of a threat to safety, fear, and helplessness. It is one's perception of danger and their personal psychological reaction that comprises their own appraisal of an event being traumatic or not (Stallard, Velleman, \& Baldwin, 2001). 
On the north side of the city, trauma was assessed to be more a static part of life and therefore emergency events were often not appraised by first responders as being as traumatic for children. Whereas, on the south side of the city emergency events were often more appraised as traumatic for children and out of the ordinary, but rather normative events. Many types of Adverse Childhood Experiences (e.g., physical and emotional abuse and neglect, domestic violence, death, mental illness) were described as common experiences of children by first responders on the north side (Kalmakis \& Chandler, 2015). Therefore, services and interventions aimed at mitigating trauma must be directed and individualized to the specific needs of the various individuals being served. Services supporting each of these groups would need to take into account the personal appraisal of trauma for each group and adapt services to support those personal appraisals.

Using a trauma-informed perspective, the observant reactions might be most concerning as these children are often not included as victims or survivors of an event needing support, but are experiencing a lot of trauma exposure through the sensory experience of observation. Furr and colleagues (2010) identified the subjective reaction of others and witnessing the disaster as being inclusive of aspects of trauma exposure. There is also a dose-response relationship between exposure and the traumatic effects on individuals, therefore, this observation with little support could be one of the most detrimental for children (Pfefferbaum, Jacobs, Griffin, \& Houston, 2015a).

Several times during interviews, first responders also described their own emotional reactions and coping in relation to emergency events involving children. The personal impact on first responders when working with children during emergency 
events, especially those they felt helpless in, was made clear. Their ideas of additional training, which would presumably increase feelings of competence, could potentially have an impact on first responder's own mental health as well as the children's. Stamm (2010) supports this conclusion, supporting that those first responders who are more likely to experience compassion satisfaction were those who felt effective in making a difference to individuals and the community they served. In addition, training also has an important influence on how first responders cope with their daily work. Negative psychological outcomes were less for those first responders that were trained versus those that were volunteer first responders (Perrin et al., 2007).

\section{Roles of First Responders}

First responders described the various ways they try to support children during emergency events: providing distraction, calming and reassurance, and education. While in some cases their descriptions were well-aligned with evidence-based practices for trauma-informed care and psychological first aid, other times, they were not quite getting it right.

While some first responders identified an assessment was needed prior to utilizing distraction, others seemed to think distraction was always the best goal. Enhancing first responders' knowledge of various coping styles (e.g., problem-focused, emotion-based, active, passive) would be beneficial in helping first responders utilize more effective methods of individualized support during emergency events involving children. Some children cope best with more information (i.e., active), while others cope best with knowing less information (i.e., passive). Distraction might be most effective for those who seek less information, while distraction for those seeking more information might be 
more stress inducing. In this instance, providing further education, information related to what they are doing to help, and statements aimed to calm and reassure might be most effective.

\section{Current Systems of Support}

When support for children was described, most often it was indicated to either come from the fire fighters themselves (discussed above), neighbors present, police called to the scene, or after a transfer to a hospital from "social service" types. When family was discussed, it often was indicated that they were more absorbed into the emergency event itself and support for children as bystanders was less a role they filled.

Perceptions of police support availability did vary amongst first responders in this study. The neighborhood context seemed to play more of a role in this difference - those in the south side indicated the police being less available, whereas, those on the north side indicated police response was almost automatic when children were involved in an emergency event. This directly relates to the stretch of available resources in the various communities and the compounding impact this has on support provided and available for children. In addition, the community's receptiveness to the police force in general was discussed by almost all the first responders as being a barrier to the police officer's efforts of providing support. This indicates, that despite potential for more availability, police officers might not be the most effective means of support to children on the scenes of emergency events.

Hospital staff, specifically, "social service" types were mentioned frequently regarding personnel that support children during emergency events. Many first responders indicated that their goal was to get off the scene and to the hospital as quickly 
as possible to access the support staff readily available at hospitals. First responders recognized this dedicated and trained support staff as useful, effective, and as a resource not available outside of the hospital to those involved in emergency events.

\section{Gaps in Services}

It became clear during interviews and data analysis that first responders' top priorities are medical care and safety. While many of them described providing direct supportive services to children on the scenes of emergency events, this service was not guaranteed when medical care took priority or resources were tight. First responders described their organic competency building in providing this type of support to children on the scene, but also recognized that other professionals are trained for this role, do this on a regular basis (i.e. hospital staff, social workers), and therefore would likely would be more effective in mitigating any potential trauma experienced by children. While ideal, there are potential barriers to providing this type of specialized and dedicated support that would need to be overcome. First and foremost, if this was an integrated emergency service, there likely would be financial and political barriers. Logistically, it would also be necessary to have someone who is readily available and promptly able to respond to emergency calls, much like the first responders. If this was a service integrated as more of a partnership, like the American Red Cross, more flexibility might be gained, political and financial barriers potentially overcome, but the direct referrals would solely rely on the assessment by the fire administrator (e.g., Fire Captain or Chief) on the scene. Thus, the referral would likely be called in once time allowed, and specialized and dedicated support would provide services post-event versus on the scene during an event. Providing education to first responder administration on services available for children who are at 
greater risk for experiencing an emergency events' traumatic effects would be essential for any new resource in the community to be utilized. In addition, that new resource would need to be connected through the appropriate channels to "Fire Alarm" who would essentially dispatch this specialized and dedicated service for children.

Given the known vulnerability of children and the potential for long-term detrimental effects, it is important that further education and training is provided to first responders to help them respond most effectively to children during emergency situations. Simplifying this training to include basic methods of providing Psychological First Aid (e.g., establishing contact, addressing basic needs, protecting from further harm/exposure, listening, providing reassurance and education, assisting with coping and problem solving, and connecting to other systems of support), would be most crucial (North \& Pfefferbaum, 2013). While also validating their current use of PFA strategies that are proven to be effective (e.g., limiting exposure by "scooting out" kids, assisting in trying to calm kids and provide reassurance). Emphasizing the importance of supporting emotional reactions (not suppressing), validating and addressing fears expressed, and answering questions at a developmentally-appropriate level would need to be an essential part of this education as well. Specifically, being trained to best evaluate the children's coping needs and motivation behind children's questions would be essential. It also is important to consider formatting the training in a way that is effective in skill-building, not just knowledge-building. Utilizing case studies relevant and provided by first responders would be useful to dissect real life scenarios recently experienced. In addition, follow-up support and education would be beneficial to keep knowledge and skills fresh throughout the year. 


\section{Limitations}

A limitation of this study concerned the limited number of participants and type of first responders. In order to better understand the diverse experiences of first responders working with children during emergency events, it would be important to recruit participants from more than a few locations across the city. Given the differences between first responders experiences in north and south city, it would be important to gather more data from first responders to better understand the mechanisms behind those differences to inform best interventions and support. In addition, this study was limited to first responders within the city fire department. Given the role described of police officers with children by participants, it would be important to include police officers as part of future studies to better identify their experiences with children during emergency events. In order for support to be effective, it must be provided, but also received. Identifying how the police officers perceive their support and limitations to this support would be beneficial to further understand best practices for supporting children during emergency situations. Thus, exploring the experiences of police officers with children would be essential to understanding the overall system of support, its efficacy and its needs. 


\section{Chapter 7: Future Research Directions}

Based on these findings, it is important that police experiences with children are explored further. Police were often reported to have more time with children but were also less positively received by the community. Understanding police experiences with children would better inform a systematic trauma-informed model of support necessary to mitigate traumatic effects of emergency events on children. In addition, developing a training for first responders working with children during emergency events was indicated. It will be important to evaluate this training for its efficacy to determine changes needed to better support the needs of the first responders and those receiving services. Finally, this study was completed in a single metropolitan city in the Midwest region of the United States. It is important to understand that results would likely vary quite a bit depending on region, culture, and community, and therefore studies expand to other locations. 


\section{References}

APA Presidential Task Force on Posttraumatic Stress Disorder and Trauma in Children and Adolescents. (2008). Children and trauma: Update for mental health professionals (pp. 1-9). Washington D.C: American Psychological Association.

Arpawong, T. E., Rohrbach, L. A., Milam, J. E., Unger, J. B., Land, H., Sun, P., ...

Sussman, S. (2016). Stressful life events and predictors of post-traumatic growth among high-risk early emerging adults. The Journal of Positive Psychology, 11(1), 1-14. https://doi.org/10.1080/17439760.2014.994223

Banks, D. M., \& Weems, C. F. (2014). Family and peer social support and their links to psychological distress among hurricane-exposed minority youth. American Journal of Orthopsychiatry, 84(4), 341-352. https://doi.org/10.1037/ort0000006

Benedek, D. M., Fullerton, C., \& Ursano, R. J. (2007). First Responders: Mental Health Consequences of Natural and Human-Made Disasters for Public Health and Public Safety Workers. Annual Review of Public Health, 28(1), 55-68. https://doi.org/10.1146/annurev.publhealth.28.021406.144037

Bonanno, G. A., Brewin, C. R., Kaniasty, K., \& Greca, A. M. L. (2010). Weighing the Costs of Disaster: Consequences, Risks, and Resilience in Individuals, Families, and Communities. Psychological Science in the Public Interest, 11(1), 1-49. https://doi.org/10.1177/1529100610387086

Bowler, R. M., Han, H., Gocheva, V., Nakagawa, S., Alper, H., DiGrande, L., \& Cone, J. E. (2010). Gender differences in probable posttraumatic stress disorder among police responders to the 2001 World Trade Center terrorist attack. American 
Journal of Industrial Medicine, 53(12), 1186-1196.

https://doi.org/10.1002/ajim.20876

Cook, A., \& Bosley, G. (1995). The experience of participating in bereavement research: Stressful or therapeutic? Death Studies, 19, 157-170.

Creswell, J. (2013). Qualitative Inquiry and Research Design (3rd ed.). Thousand Oaks, CA: SAGE Publications.

Ellrich, K., \& Baier, D. (2017). Post-traumatic stress symptoms in police officers following violent assaults: a study on general and police-specific risk and protective factors. Journal of Interpersonal Violence, 32(3), 331-356.

Felitti, V., Anda, R., Nordenberg, D., Williamson, D., Spitz, A., Edwards, V., ... Marks, J. (1998). Relationship of childhood abuse and household dysfunction to many of the leading causes of death in adults: The Adverse Childhood Experiences (ACE) study. American Journal of Preventive Medicine, 14, 245-258.

Felitti, V. J. (2009). Adverse childhood experiences and adult health. Academic Pediatrics, 9(3), 131.

Furr, J. M., Comer, J. S., Edmunds, J. M., \& Kendall, P. C. (2010). Disasters and youth: A meta-analytic examination of posttraumatic stress. Journal of Consulting and Clinical Psychology, 78(6), 765-780. https://doi.org/10.1037/a0021482

Gilbert, L. K., Breiding, M. J., Merrick, M. T., Thompson, W. W., Ford, D. C., Dhingra, S. S., \& Parks, S. E. (2015). Childhood Adversity and Adult Chronic Disease. American Journal of Preventive Medicine, 48(3), 345-349. https://doi.org/10.1016/j.amepre.2014.09.006 
Halpern, J., \& Vermeulen, K. (2017). Disaster mental health intervention: Core principles and practices. New York: Routledge.

Hawkins, R. (2009). Same as It Ever Was, Only Worse: Negative Life Events and Poverty Among New Orleans Katrina Survivors. Families in Society: The Journal of Contemporary Social Services, 90(4), 375-381. https://doi.org/10.1606/10443894.3922

Hobfoll, S. E., Watson, P., Bell, C. C., Bryant, R. A., Brymer, M. J., Friedman, M. J., ... others. (2007). Five essential elements of immediate and mid-term mass trauma intervention: Empirical evidence. Psychiatry: Interpersonal and Biological Processes, 70(4), 283-315.

Husserl, E. . (1962). Ideas: General introduction to pure phenomenology. New York: Macmillan.

Jones, S. (2017). Describing the Mental Health Profile of First Responders: A Systematic Review. Journal of the American Psychiatric Nurses Association, 23(3), 200-214.

Kalmakis, K. A., \& Chandler, G. E. (2015). Health consequences of adverse childhood experiences: A systematic review: Health consequences of adverse childhood experiences. Journal of the American Association of Nurse Practitioners, 27(8), 457-465. https://doi.org/10.1002/2327-6924.12215

Karlsson, I., \& Christianson, S.-\AAke. (2003). The phenomenology of traumatic experiences in police work. Policing: An International Journal of Police Strategies \& Management, 26(3), 419-438. 
Kleim, B., \& Westphal, M. (2011). Mental health in first responders: A review and recommendation for prevention and intervention strategies. Traumatology, 17(4), $17-24$.

Ko, S. J., Ford, J. D., Kassam-Adams, N., Berkowitz, S. J., Wilson, C., Wong, M., ... Layne, C. M. (2008). Creating trauma-informed systems: Child welfare, education, first responders, health care, juvenile justice. Professional Psychology: Research and Practice, 39(4), 396-404. https://doi.org/10.1037/07357028.39.4.396

Kronenberg, M. E., Osofsky, H. J., Osofsky, J. D., Many, M., Hardy, Melissa, \& Arey, James. (2008). First Responder Culture: Implications for Mental Health Professionals providing services following a natural disaster. Psychiatric Annals, 38(2), 798-805.

Kupersanin, E. (2002). Stoic Firefighters Wrestle With Post-Disaster Emotions. Psychiatric News, 37(5), 7-37. https://doi.org/10.1176/pn.37.5.0007

Maguen, S., Metzler, T. J., McCaslin, S. E., Inslicht, S. S., Henn-Haase, C., Neylan, T. C., \& Marmar, C. R. (2009). Routine Work Environment Stress and PTSD Symptoms in Police Officers: The Journal of Nervous and Mental Disease, 197(10), 754-760. https://doi.org/10.1097/NMD.0b013e3181b975f8

Maslow, A. H. (1943). A theory of human motivation. Psychological Review, 50, 370396.

Masten, A. S., \& Narayan, A. J. (2012). Child Development in the Context of Disaster, War, and Terrorism: Pathways of Risk and Resilience. Annual Review of 
Psychology, 63(1), 227-257. https://doi.org/10.1146/annurev-psych-120710100356

Metropolitan Police Department. (2016). Annual Report --- Law Enforcement (pp. 1-67). ---: Metropolitan Police Department. Retrieved from MoDOT. (2013). --- City Crash Report (Missouri Crash Statistics). Missouri Department of Transportation.

Norris, F. H., Friedman, M. J., Watson, P. J., Byrne, C. M., Diaz, E., \& Kaniasty, K. (2002). 60,000 disaster victims speak: Part I. An empirical review of the empirical literature, 1981-2001. Psychiatry: Interpersonal and Biological Processes, 65(3), 207-239.

North, C. S., \& Pfefferbaum, B. (2013). Mental Health Response to Community Disasters: A Systematic Review. JAMA, 310(5), 507. https://doi.org/10.1001/jama.2013.107799

Osofsky, J. D. (2011). Clinical Work with Traumatized Young Children. New York: The Guilford Press.

Patton, M. . (2002). Qualitative Research \& Evaluation Methods (3rd ed.). Thousand Oaks, CA: SAGE Publications.

Perrin, M., DiGrande, L., Wheeler, K., Thorpe, L., Farfel, M., \& Brackbill, R. (2007). Differences in PTSD prevalence and associated risk factors among World Trade CEnter disaster rescue and recovery workers. American Journal of Psychiatry, 164(9), 1385-1394.

Perry, B. D. (2006). Applying Principles of Neurodevelopment to Clinic Work with Maltreated and Traumatized Children: The Neurosequential Model of 
Therapeutics. In Working with Traumatized Youth in Child Welfare (pp. 27-52). New York: The Guildford Press.

Perry, B. D. (2008). Child maltreatment: the role of abuse and neglect in developmental psychopathology. In Child and Adolescent Psychopathology (pp. 93-128). New York: Wiley.

Perry, B. D. (2009). Examining child maltreatment through a neurodevelopmental lens: clinical applications of the neurosequential model of therapeutics. Journal of Loss and Trauma, 14(4), 240-255. https://doi.org/10.1080/15325020903004350

Pfefferbaum, B., Jacobs, A. K., Griffin, N., \& Houston, J. B. (2015a). Children's Disaster Reactions: the Influence of Exposure and Personal Characteristics. Current Psychiatry Reports, 17(7). https://doi.org/10.1007/s11920-015-0598-5

Pfefferbaum, B., Jacobs, A. K., Griffin, N., \& Houston, J. B. (2015b). Children's Disaster Reactions: the Influence of Exposure and Personal Characteristics. Current Psychiatry Reports, 17(7). https://doi.org/10.1007/s11920-015-0598-5

Pfefferbaum, B., Jacobs, A. K., Houston, J. B., \& Griffin, N. (2015). Children's Disaster Reactions: the Influence of Family and Social Factors. Current Psychiatry Reports, 17(7). https://doi.org/10.1007/s11920-015-0597-6

Porter, E. J. (1995). The life-world of older widows: The context of lived experience. Journal of Women \& Aging, 7, 31-46.

Porter, E. J. (1998). On “Being Inspired” by Husserl's phenomenology: Reflections on Omery's exposition of phenomenology as a method of nursing research. Advances in Nursing Science, 21(1), 16-28. 
Porter, E. J., \& Cohen, M. (2012). Phenomenology. In Reviewing Qualitative Research in the Social Sciences (1st ed., pp. 180-196). New York: Routledge.

Roepke, A. M. (2015). Psychosocial interventions and posttraumatic growth: A metaanalysis. Journal of Consulting and Clinical Psychology, 83(1), 129-142. https://doi.org/10.1037/a0036872

Rossetto, K. R. (2014). Qualitative research interviews: Assessing the therapeutic value and challenges. Journal of Social and Personal Relationships, 31(4), 482-489. https://doi.org/10.1177/0265407514522892

Sacks, V., Murphey, D., \& Moore, K. (2014). Adverse Childhood Experiences: National and State-Level Prevalence (Research Brief No. 2014-28). Child Trends.

Shakespeare-Finch, J. E., Smith, S. G., Gow, K. M., Embelton, G., \& Baird, L. (2003). The prevalence of post-traumatic growth in emergency ambulance personnel. Traumatology, 9(1), 58.

Stallard, P., Velleman, R., \& Baldwin, S. (2001). Children involved in road traffic accidents: psychological sequelae and issues for mental health services. Clinical Child Psychology and Psychiatry, 6(1), 23-39.

Stamm, B. . (2002). Measuring compassion satisfaction as well as fatique: Developmental history of the Compassion Satisfaction and Fatigue Test. In Treating compassion fatigue (pp. 107-119). New York: Brunner-Routledge. Stamm, B. . (2010). The ProQOL (Professional Quality of Life Scale: Compassion Satisfaction and Compassion Fatique). ProQOL.org. 
Steele, W. (2009). Trauma informed care: A history of helping: A history of excellence lessons learned since 1990: (551032013-001) [Data set]. American Psychological Association. https://doi.org/10.1037/e551032013-001

Stinchcomb, J. B., \& Ordaz, F. (2007). The Integration of Two "Brotherhoods" into One Organizational Culture: A Psycho-social Perspective on Merging Police and Fire Services. Public Organization Review, 7(2), 143-161. https://doi.org/10.1007/s11115-006-0026-8

Tedeschi, R. G., \& Calhoun, L. G. (1996). The Posttraumatic Growth Inventory: Measuring the positive legacy of trauma. Journal of Traumatic Stress, 9(3), 455471.

Ursano, R. J., \& McCarroll, J. (1990). The nature of a traumatic stressor: Handling dead bodies. Journal of Nervous and Mental Disease, 178(6), 396-398.

Van Der Kolk, B. A. (2005). Developmental Trauma Disorder. Psychiatric Annals, 35(5), 401-408.

Vernberg, E. M., Steinberg, A. M., Jacobs, A. K., Brymer, M. J., Watson, P. J., Osofsky, J. D., ... Ruzek, J. I. (2008). Innovations in disaster mental health: Psychological first aid. Professional Psychology: Research and Practice, 39(4), 381-388. https://doi.org/10.1037/a0012663

Wooding, S., \& Raphael, B. (2004). Psychological Impact of Disasters and Terrorism on Children and Adolescents: Experiences from Australia. Prehospital and Disaster Medicine, 19(01), 10-20. https://doi.org/10.1017/S1049023X00001436 
Woody, R. H. (2005). The Police Culture: Research Implications for Psychological Services. Professional Psychology: Research and Practice, 36(5), 525-529. https://doi.org/10.1037/0735-7028.36.5.525

Yin, R. (2011). Qualitative Research from Start to Finish. New York: Guilford Press. 


\section{Appendices}

\section{Appendix A. Interview Protocols}

\section{First Interview Protocol}

To begin, I'd like to gather a little bit more about your background:

- What is your official job title? How long have you been in this specific role?

- How long have you been serving as a first responder? What other first responder roles have you filled?

- How long have you been serving in this specific department?

As you know from consent, I'm interested in learning about your experiences working with children during emergency events. I want to remind you that participation is voluntary, and you are welcome to stop participation at any time. In addition, all of your answers will be kept confidential and will not be identifiable other than from your first responder role and within a Midwest Metropolitan Fire Department.

- Can you tell me about a recent time when you responded to an event and children were involved?

- What were the reactions of the children?

- What was your interaction with the children and caregivers?

- Who provided support to the children?

- Can you tell me about a particularly significant time when you responded to an event and children were involved?

- What are the current systems providing children with support during emergency events? 
- How would you identify your role in the emotional support of children during emergency events?

- How does this role, align with other roles you have on the scene?

- What resources are available to first responders for working with traumatized children?

- Have you received any type of training or education regarding working with children?

- Are there resources you desire?

- Are there specific professionals or organizations you work with? 


\section{$\underline{\text { Second Interview Protocol }}$}

Since our last interview...

- Have you had any specific thoughts about the topics we discussed?

- Have you had any encounters with children that stood out? Tell me about them.

- What were the emotional reactions of the children?

- What was your interaction with the children and caregivers?

- Who provided emotional support to the children?

- Have you been exposed to any other systems of support or organizations providing children with emotional support during emergency events that you previously were unaware?

- Are there any protocols that you have become aware?

- Is there anything else you wish to share? 


\section{Appendix B. Consent form}

\section{INVESTIGATOR'S NAME: LINDSEY MURPHY \\ ProjeCT \#: 2010794}

\section{STUDY TITLE:}

THE LIVED EXPERIENCES OF FIRST RESPONDERS DURING TRAUMATIC EVENTS INVOLVING

CHILDREN

\section{INTRODUCTION}

You are being invited to take part in a research study. This research is being conducted to gain insight from first responders about their experiences working with children during traumatic events. You have the right to be informed about the study procedures and know what will be asked of you to participate, in order for you to decide whether you want to consent to participate in this research study or not. Your participation is voluntary. You do not have to be in the study; you may refuse to be in the study without any penalty at any time throughout the study.

I ask that you read this form and ask any questions that you may have before enrolling yourself to participate in this study.

\section{DESCRIPTION OF THE RESEARCH}

You have been invited to be in this study because you are an expert in emergency response and have experiences working with children during potentially traumatic events (e.g., accidents, fires, medical events). Your insight into the emergency response systems and your lived experiences working with children will be valuable insight to help build a systematic model of support for children enduring the effects of traumatic events.

\section{Procedures OF THE STUDY}

If you agree to be a part of the study, you will be asked to engage in up to three separate semi-structured interviews with a research investigator at the time, date, and location of your choice (preferably a private space at your place of work).

\section{HOW LONG WILL I BE IN THE STUDY?}

This study will take place over the span of a few months, with each interview lasting approximately 30-60 minutes. Interviews can be stopped, paused, and restarted at any time and will never interfere with work expectations or requirements. You can stop participating at any time without penalty.

\section{HOW MANY PEOPLE WILL BE IN THIS STUDY?}

The research aims to have approximately 20 first responders enrolled in the study. First responders including firefighters, emergency medical technicians, and paramedics will be enrolled. Your department is one of several places being sought for participants, not all participants will be your colleagues. 


\section{WHAT ARE THE BENEFITS OF THE RESEARCH?}

By participating in this research, you may experience increased role satisfaction as you will have an opportunity to extend knowledge to those less informed about these events than yourself. In addition, you may experience satisfaction in knowing that you are contributing to science that aims to inform a systematic support system for children experiencing traumatic events.

\section{WHAT ARE THE RISKS OF THE RESEARCH?}

By participating in this research, you may experience discomfort related to the retelling of traumatic events. You are encouraged to stop sharing if discomfort arises, and seek professional support through the department resources.

\section{PARTICIPATION IS VOLUNTARY}

Participation in this research study is voluntary. You may refuse to participate or withdraw yourself from the study at any time, with no type of penalty.

\section{WHAT ABOUT CONFIDENTIALITY?}

You will be audio recorded during this study. I will do my best to make sure that your answers to these questions are kept private. Information produced by this study will be stored in the investigator's file and identified by a code number only. The code key connecting your name to specific information about you will be kept in a separate, secure location. Information contained in your record may not be given to anyone unaffiliated with the study in a form that could identify your employee without your written consent, except as required by law. In addition, information about your place and location of work will also be de-identified. For the purposes of this study, your place of work will be a "Midwest metropolitan fire department."

\section{WHO CAN I TALK TO ABOUT THE STUDY?}

If you have any questions about the study or if you would like additional information, please call Lindsey Murphy at 314-930-5771 or Lmzn7d@ missouri.edu or Dr. Sarah Killoren at Killorens@missouri.edu. You may contact the University of Missouri Institutional Review Board (which is a group of people who review the research studies to protect participants' rights) if you have questions regarding your employee's rights as a research and/or concerns about the study, or if you feel under any pressure to enroll your employee or to continue to participate in this study. The IRB can be reached directly by telephone at 573-882-3181.

\section{CONSENT}

I have read this consent form and have been given the opportunity to ask questions. I give my permission to participate in this study. I understand that participation is voluntary and I can withdraw at any time without penalty or loss of benefits. You will be informed of any significant new findings discovered during the course of this study that might influence your health, welfare, or willingness to continue participation in this study. Date: 


\section{Appendix C. Recruitment Script}

Hi [Title \& Name],

I'm reaching out today with permission from Captain --- and the --- Fire Department to request your participation in a research study I am conducting. As a $\mathrm{PhD}$ candidate at University of Missouri, I am working on my dissertation titled "The Lived Experiences of First Responders During Traumatic Events Involving Children." You are being asked to participate as you are considered an expert in your field with experiences working with children in potentially traumatic situations as a first responder within the --- Department. Your expertise in these areas will best inform a systematic approach to trauma-informed care for children and families being affected.

The research will consist of up to three separate 30-60-minute audio-recorded semistructured interviews, conducted over the span of a few months. The interviews will focus on learning about your experiences and observations working with children in traumatic events. The time, date, and location of these interviews will be mutually agreed upon and convenient for both parties. Participation is voluntary and confidential. There are no repercussions for not participating. Participation can also be stopped at any time. All data collected will be coded and de-identified.

If you have any questions or would like to participate in the research, I can be reached at 314-930-5771 or Lmzn7d@ missouri.edu. Looking forward to hearing back from you. 


\section{Appendix D. Debriefing Protocol}

Throughout the interviews, the researcher will provide reflective and empathetic listening, validate the participants expressed feelings, and provide positive words of affirmation whenever possible.

At the completion of the interview, the researcher will utilize positive affirmation to validate the participant's efforts for a job well done with children in these situations. The researcher will then follow this script:

"It is obvious that you do a very difficult job day in and day out. Thank you for that from both myself and the community. Despite its difficulty you come back each shift, what keeps you going? What do you love most about this job and the community you interact with?"

"It sounds like you have a great network around you for support. I know we have discussed some tough topics today, in addition to your existing support network, I wanted to provide you with this handout of additional resources and support that might be beneficial in some way either now or in the future." 


\section{Appendix E. Excerpt from researcher's journal}

$\underline{\text { April 16, } 2018}$

Throughout my lifetime, I have continuously been drawn to trauma and emergency response systems. As a kid, I would always try to get my parents to follow fire trucks and ambulances to see what was going on - I was an adrenaline rush kind of kid. As an adolescent and young adult, I discerned what career might be most meaningful and suitable to my strengths. At several points I considered becoming a first responder. Each time I came back to the conclusion that I really wasn't interested in the physical support, but rather the psychological and emotional support. This led me to a career in child life, working with children and families in stressful circumstances. I landed my first job as a Certified Child Life Specialist in a Level 1 trauma center in one of the busiest Pediatric Emergency Departments in the country. During these years, I learned just how tragic life could be - what it meant to hold a parent's hand as they watched their child die, how to support a sibling after they accidentally shot their twin, and the list goes on and on. It was during many of these encounters that I realized I had a passion for this work, but really wanted to start that work prior to their arrival at the hospital. I knew that if I had been able to mitigate some of what they experienced on the scene and utilize the ambulance ride to prepare them for the trauma bay, I might observe more resilience in the face of trauma.

After a few years in the Emergency Department, I transitioned to work in the Department of Developmental and Behavioral Pediatrics (DDBP) at the same hospital at the time the move was primarily to gain a better schedule and I thought I was leaving something I loved so dearly. Little did I know it would be part of my growing passions 
and contribute greatly to my understanding of trauma. In DDBP I encountered children with a whole page full of diagnosis who had experienced one set back after another. I began to wonder how much of their diagnoses would have been prevented had their initial and ongoing trauma been treated or acknowledged. About this time, I went to a conference and got introduced to Dr. Bruce Perry's work in trauma, he quickly became my idol - his Neurosequential Model of Therapeutics (NMT) gave me the brain science behind trauma and resilience that I desperately needed to more fully understand trauma and intervention.

About this time, several international and national disasters rocked the world. A like-minded colleague and I began to discern how child life specialists could serve children and families during disasters. After a hand shake and our first business meeting at a local coffee shop, we went on an endeavor to: a) find out what support was already being provided to children and families; b) find out if there were any gaps; and c) find out if the child life skill set could meet any of those gaps. Since then our organization has grown to become a 501(c)(3) with over 1000 Certified Child Life Specialists as members, serving in over 25 major disasters. After several years serving in national man-made and natural disasters we are recognizing the need to integrate on the local level, during smaller scale disasters and/or crisis. This is primarily for two reasons. First, the trauma that happens during larger national disasters is quite visible, but what often goes unrecognized is the trauma that happens in our own backyards, those that are happening nearly every hour - car accidents, home fires, homicides, physical injuries, etc. It is events like these that can lead to alternative developmental trajectories, further diagnoses, adverse behavioral outcomes, and major health issues later in life if not supported. 
Second, we feel local integration of our services will assist the integration of our services in the earlier phases of larger scale national disasters. During large scale national disasters, we are primarily serving during the response and honeymoon phase of disasters in shelters or resources centers providing child-directed therapeutic play opportunities, support, and psychoeducation. While extremely valuable and important, major gaps in psychological support and services in the acute phase of disasters exist. It is during the acute phase of disasters that local entities, organizations, and services are responding. Thus, it is essential to already be a networked and integral part of these local services on a daily basis, in order to be called upon to support during larger scale national disasters.

Over the years, I have been friends, coworkers, and acquaintances with many first responders. It is through casual conversations with these first responders about our shared passions that I have begun to gain insight into their experiences working with children. Many times, these peers seek me out as someone who has expertise with children to validate what they did or to seek advice for what would have been a best approach. They have revealed their simultaneous discomfort with their competency in working with children and their desire to help. They also often talk about the impact working with children has on their own mental health. It is many of these conversations that have contributed to my interest in learning more about first responders experiences working with children and how they contribute and perceive their role in the mental health of those children affected by traumatic events.

It is through my dissertation that I hope to gain a better understanding of this emergency response field and the players involved in it. I hope to gain a better understanding for what roles people have and what services are being provided by whom 
to support the children and families affected. Ultimately, I hope to answer the same questions we did on the national level: a) find out what support is already being provided to children and families; b) find out if there were any gaps; and c) find out if the child life skill set could meet any of those gaps. I believe going to those working in the field as experts will not only help to gain an understanding of the needs in the community, but also help to begin building relationships and networking which will be essential when integrating services into a new field.

November 3, 2018

Today was my experience in the fire department and first interview. I spent about three hours hanging out in the kitchen with a group of fire fighters before completing my first interview, with the known first responder. It was so interesting to observe their interactions with each other and myself during these three hours. I quickly learned that the known first responder was somewhat newer to this fire house, his interactions were in some cases more formal with colleagues and in others more friendly - I could tell who he had more rapport and comradery with in the house. There was one colleague in particular who when introduced to myself and my purpose for being there, seemed to be quite skeptical and "put on a show." I was hounded with questions left and right about my intentions, but mostly in a sarcastic way - where no matter my answer he wasn't going to be satisfied. Based on his questions, I could tell he was somewhat thinking about the research on a deeper level and I appreciated this. I also felt like this was somewhat of a test or "hazing" into the fire department culture - "Can this gal handle what I throw her? How will she respond? Can she handle stress?" kind of thing. At some points, I didn't know if I should handle his questions seriously or if I should throw sarcasm back at 
him...there was a little of both and worked hard to remain calm and relaxed...phew! The known first responder laughed through much of this rigamarole, I'm not sure he knew if it was serious or not. In fact, I later asked him privately and he said he was just as confused, but thought I handled it well.

After hanging out, the known first responder invited me to complete his first interview. He also inquired amongst his colleagues if anyone else would be willing and three others agreed to be interviewed at later dates. Woo hoo! This first interview went well, but there were a few things that stood out to me. At first, he kept stories pretty brief and kept checking in to see if that was what I was wanting... when probed with more questions about the events he easily answered those questions in more detail. After a little of this he began to share experiences with more detail with less probing. I had to work hard to maintain appropriate nonverbal and verbal reactions throughout the interview. I wanted him to feel validated in his actions on the scene, while also validated in his demeanor when telling about his experiences. In some instance, he spoke candidly and more matter of fact about serious situations, while in others I could tell he spoke more seriously and had a lot more of an emotional or mentally charged response to recalling the events. I tried to match this demeanor and support these experiences as best as possible in my own communication back. In addition, one thing I was not expecting was that once I turned off the recorder to officially end the interview, we stayed and chatted about his experiences with children for another thirty minutes or so. At the time, I was so bummed and trying to remember all that I could about what he was sharing because I knew it wouldn't be recorded. However, I also was grappling with why he might have waited to share these things until after I turned off my recorder. He actually 
said, "I wasn't going to share this one, but..." before beginning an intense story about a child whom his squad had built a relationship with that ended up coding in their firehouse and dying. It was clear that this story sat with him much deeper than any of the others he shared with me that day. I feel like it was his way of protecting himself from demonstrating that emotional reaction during the recorded interview or maybe it was because the interview itself wasn't long enough to gain his comfort to share such an intimate story yet, but afterwards he felt that comfort? Who knows...something I definitely will keep in mind and why I am so grateful I am doing multiple interviews with each person, I hope that the consecutive interviews and visits will encourage more trust and rapport to be built, enabling these sorts of stories to be told.

\section{November 12, 2018}

Today I revisited the fire house to complete three more scheduled interviews. I felt more at ease during this visit, because I had already gotten to know some of the first responders, what to expect, the culture, etc. I intentionally didn't push the interview agenda as soon as I got there, I sat down with the people hanging out in the kitchen for another few hours before asking if any of the three were ready to be interviewed. Again, this time spent was useful to gain trust and rapport as well as gain more insight into the fire department culture and services. Their stories about calls and jokes they play on each other in the fire house helped me to get a better understanding of how they work together and how their services are rendered during events. During my time there today the "bells" dropped several times and certain people jumped into action for various types of calls. It was interesting to see their reactions to each call depending on what it was most of them were for medical reasons. One time they listened to the information about 
the call and then nodded to each other, "that's so and so again..." referring to a regular medical patient they were familiar with...they seemed in less of a hurry with less adrenaline. I noticed when the one fire call came in there was a different sense of urgency and a lot more of the first responders jumped into action. I couldn't help myself but get excited every time I heard the bells drop, but I tried to play it cool and act unphased...it was so interesting to hear what information they receive and how when the bells dropped.

One thing that stood out to me during this set of interviews was that none of the first responders so far wanted to take my "resources and support" page that gave them places and services to call if they were emotionally distressed. While none of them appeared distressed post interview, several of them did talk about how much they feel for these patients and people in those situations. Regardless, they all quickly turned my resource down, regardless I still left a copy in the office and told them I had done that. While, I somewhat predicted no one would take it, what reading I had done on first responder culture told me that they might be resistant to demonstrating a need for resources like this, I was still surprised no one took it and put it in their pocket when no one else was looking.

I also felt like during these interviews I got better as the interviewer at asking better questions that led more directly to my research questions. For instance, I realized that when I was just asking them to tell me about a time they responded to an event and children were involved, I was often getting children as the most critical patient that may have or may not have survived, which wouldn't be super relevant to psychosocial support. But when I followed that question with "Tell me about a time when you 
responded to an event and children were not the most critical patient or the bystanders" I tended to get more relevant scenarios described.

I also found it quite interesting today that the fire fighter who gave me so much grief during my first visit to the house, acted completely different today. It was almost like that first day he put on a show to test the waters with me. Today, he was much more serious, easier to talk to and read, and didn't use hardly any sarcasm. The first day I was worried that maybe when I did get to interview him he wouldn't take it seriously, but that was the exact opposite of what happened today. He seemed to take it really serious. When walking out with the known first responder today, he asked how things went and I mentioned how different this first responder acted today and how much easier it was to read him - he laughed and said "yeah I think that was all a show to feel you out the first day! He really is one of the nicest and talked after you left the other day about how intrigued he was about your research topic."

$\underline{\text { November 30, } 2018}$

Today, I went to the second fire house to hang out, introduce myself, etc. I was connected with this fire house through a family member's friend, but I wasn't sure what all that friend had shared with his colleagues about me coming. I also was a little on edge driving there because my family had warned me about it really not being a safe place in town to drive, park, etc. I was sure to text the first responder friend just prior to my arrival so that I knew he would be watching me walk into the house from my car and I wouldn't be waiting on the sidewalk like a lone duck - worked like a charm. Upon my arrival, I again was directed to the kitchen where his entire squad of four (all the occupants of this firehouse) were hanging out. It was obviously a much smaller fire 
house than my last one. I again hung out here for several hours chatting with them. It wasn't until two hours in that I realized their Captain was one of those among them, whereas, at the last house, I only was formally introduced to the captain and he had very little interaction with myself and the first responders while I was there. Perhaps, this is the difference between a large and small fire house.

I could immediately tell the culture of this house was different than the last. They seemed much more serious and immediately wanted to dive into topics related to my research - they were eager to share. I had a little bit of trouble deciphering what conversations I wanted to avoid and save for interviews and which conversations to just go ahead and engage in as a group. During these group conversations I learned a lot about the city, its population specifically, and quickly gained an understanding that my family was right - this was a much less safe area of the city than where I was prior. At first, I was hesitant to share that assumption because I didn't want to assume or for them to sense my discomfort in their service area, but they brought it up and made a safety plan with me because of the reality of their area being unsafe - even to them. All of them stated at some point that they don't even let their wives or children visit them while they're at work.

I wasn't sure if I was going to complete any interviews today, but all four of those in the house today actually let me interview them on their own accord. At first, I was nervous we hadn't had enough rapport building time since I had planned to have to come back an entirely different day, but after spending so many hours with them all in group conversation I felt like they were ready. My interviews seemed to go really well and I was taken back by the way they answered questions about their experiences with children 
and expressed their ideas on resources needed. I don't think I had taken into account how varied different areas of the same city could be in regards to population served. The first responders described extreme poverty, a lack of resources, and lots of drugs and violence in the area. Whereas, in the last house these things weren't discussed a lot when talking about responding to emergency events. The first responders here focused a lot on how their mindset had changed after working in this particular house and how they try to be a positive influence in this community. I'm beginning to understand that trauma-informed services provided on the basis of an emergency event, might not even scrape the trauma these children experience on the daily basis. Many of the first responders described children not seeming affected by them arriving on scene, the emergency events themselves, or violence in their neighborhoods. In group conversation, the fire fighters even described how they were cleaning up the streets of blood and gore after a shootout in the neighborhood and kids were just walking over the bloody sidewalks like it was sidewalk chalk or something. Like no big deal, something they see on the regular. Mind blowing to the fire fighters and myself.

$\underline{\text { January } 29,2019}$

Today, I revisited fire house \#2 and also went to a third fire house to catch up with a fire fighter who had been transferred since our last interview. After catching up for a bit and having casual conversation, they decided to jump right into interviews. I later found out this may have been due to another commitment that day - they had to attend a memorial for a fallen police officer. I could tell when I entered the fire house there was a more somber mood, and unfortunately, I had anticipated this due to hearing about the police officer on the news. I even checked to make sure it was still a good day 
for me to visit, before driving out there, they reassured me it was good to come. I could tell when interviewing them today that they were more relaxed this time around. I think for them, they had a better sense of my intentions and questions, they knew what to expect. For me, I knew them better and felt more comfortable as the interviewer. I got to talk with them each more about their experiences with children, their perceptions of their needs, and the resources that would be most helpful. It was interesting to hear that the resources most often mentioned were what I would consider foundational - access to food, beds, clean environments, parental education, etc. - the basic necessities. They weren't as often mentioning resources related to coping or dealing with what the first responders were specifically called in for - a fire, medical emergency, parental drug overdose, injury, etc. This is important to recognize as I continue to seek out ways to integrate a trauma-informed care model to support children in these areas. As a Certified Child Life Specialist, those basic needs wouldn't necessarily be in our scope, but as a member of the community how might I be able to support these needs through other means of advocacy, collaborating across disciplines, and resource building?

When I visited the new house today, it wasn't the ideal setup. They had a lounge area and a kitchen area where people were hanging out, no private office was available. So the interviewee asked the others to leave the kitchen, however, one first responder stayed in order to continue cooking dinner for the house. I wasn't sure how this would affect the interview, but it wasn't something I had much control over. I asked the interviewee several times if he was comfortable or if he wanted me to come back another time, he reiterated that this setup worked for him if it did me - so I went with it. During 
the interview, it actually came in a little handy as the first responder who was cooking and had many more years of experience within the city fire department chimed in a few times about resources the interviewee didn't know about. I also was concerned that the noise from cooking was going to interfere with the recording, but luckily it didn't. This interview was a little shorter than the others I had done that day, we got cut off by the bells dropping and my interviewee had to respond, luckily, we were wrapping things up anyways.

January 30,2019

Today, I revisited my first fire house again to complete second interviews. Like yesterday, there was less hanging out time and we seemed to get to interviewing a little quicker. It was nice to get time with those I interviewed first again, because I felt like those were the less productive interviews due to my own comfort level and experience. I was able to ask questions that better answered my research questions that I didn't ask prior. I could also tell, like the other interviewees, the fire fighters were more at ease this second time around - I'm continuously feeling validated that I chose the right methodology for this type of research.

I also asked a lot more questions about the population they serve in this area, since this had come to the forefront at the other house. I wanted to learn more about how the fire fighters here described their area of town. Interviews didn't last as long today, I think mostly because they hadn't responded to a whole lot of new events involving children since our last conversations. I asked questions to clarify some of the phenomenon I had begun to analyze based on first interviews and was validated numerous times I was on the right track, this was helpful to know! 
February 17,2019

Today, I completed my final two interviews with first responders. I met one at a new fire house in town and the other met me at a public library private room. I was extra appreciative of the one meeting me at the library to complete the interview as he was on his personal time off and agreed to still meet me. When I expressed this, he reiterated that he was just happy to help and glad someone was thinking about how to add support to the children they work with on the daily basis - this was really nice to hear.

Given the time between the last interviews and these final interviews, I really was able to sift through all my data and identify anything I needed to still ask from first responders. Today's interviews really helped solidify that the phenomena I was identifying were in fact what first responders were depicting. Despite my mind racing about all the next studies and future directions, I am glad to have this sense of completion for data collection on this project, it's nice to know that data collection is complete and to have a sense of peace as a researcher about that. 


\section{VITA}

Lindsey M. Murphy was born December 30, 1986 in St. Charles, MO. She attended private school and went on to receive her Bachelor of Science in Child and Family Development, emphasis in Child Life, from Missouri State University in December 2008. While practicing as a Certified Child Life Specialist at Cincinnati Children's Hospital Medical Center, she earned her Master of Education in Education and Counseling Psychology, emphasis in Mental Health, from University of Missouri in December 2012. In pursuit of elevating the field of Child Life through research, teaching, and service she then earned her Doctor of Philosophy in Human Development and Family Science from University of Missouri in May 2019. 